\title{
Custo Leite para Windows: Software de Controle de Custos para a Pecuária Leiteira Marcos Aurélio Lopes ${ }^{1}$, Frederico do Valle Ferreira de Castro ${ }^{2}$, Francisval de Melo Carvalho ${ }^{3}$, André Luiz Zambalde ${ }^{3}$, Delmara de Cássia Fernandes Lopes ${ }^{4}$
}

\begin{abstract}
RESUMO - O objetivo deste trabalho foi desenvolver um software para auxiliar os técnicos e produtores na determinação do custo de produção do leite. O software Custo Leite é composto de um plano de contas, no qual o usuário pode cadastrar todas as despesas e receitas referentes ao sistema de produção de leite. O software permite o cadastramento de todos os bens móveis e benfeitorias do sistema de produção, visando aos cálculos de depreciação e remuneração do capital. O Custo Leite calcula e apresenta ao usuário as seguintes variáveis: total das receitas, total dos custos operacionais, custo total, margem bruta, margem líquida, lucro, custo operacional e custo total por kg de leite, ponto de equilíbrio do sistema de produção, quantidade total de leite produzido, valor do patrimônio, remuneração do capital, produção média das matrizes ( $\mathrm{kg} / \mathrm{dia}$ ) e produção de leite em $\mathrm{kg} / \mathrm{ha} / \mathrm{mês}$. O software permite ao usuário diversas simulações envolvendo todos os parâmetros e variáveis, mostrando os pontos de estrangulamento e auxiliando o técnico e o pecuarista na determinação do custo de produção do leite com precisão e considerável rapidez.
\end{abstract}

Palavras-chave: custo de produção, gerenciamento, informática, pecuária leiteira, simulação, sistema computacional

\section{Milk Cost for Windows: Cost Control Software for Dairy Cattle Production}

\begin{abstract}
The objective of this work was to develop a software to assist the technicians and producers in the determination of the cost of production of milk. The Milk Cost is made up of a plan of calculations encompassing both expenses and incomes. The user can put into a spreadsheet all the expenses and incomes concerning to the milk production system. The software enables the spreadsheet of all the estates and facilities of the production system, aiming the calculations of depreciation and remuneration of the capital. The Milk Cost calculates and presents to the user the following variables: total of the incomes, total of the operational costs, total costs, gross margin, net margin, profit, operational cost and total cost per kilogram of milk, break even point of the production system, total amount of milk produced, value of the property, capital remuneration, average yield of the cows ( $\mathrm{kg} / \mathrm{day}$ ) and milk yield in $\mathrm{kg} / \mathrm{ha} /$ month. The system enables the user a number of simulations involving all the parameters and variables, showing the strangulation pointstand helping both the technician and the stockman to determine milk production cost with precision and considerable quickness.
\end{abstract}

Key Words: computer science, dairy cattle, management, production cost, simulation, software

\section{Introdução}

A bovinocultura de leite é uma atividade de grande importância na economia do Brasil, por manter elevados percentuais do valor da produção agropecuária e também por gerar milhares de empregos diretos.

A revolução científica provocada pelas novas tecnologias da informação repercute sobre o sistema produtivo como um todo, e a pecuária não poderia ficar imune, embora esta revolução tenha se iniciado tardiamente, nessa atividade, quando comparada a outros setores produtivos. Mesmo assim, devido à nova consciência que está se formando e à significativa redução dos custos na informatização, o setor primário da economia brasileira está abrindo suas portas à revolução da informação, da mesma forma que os setores industrial e de serviços o fizeram há mais de 10 anos (ANTUNES e ANGEL, 1995).

No processo de informatização e modernização da bovinocultura, existem diversas aplicações e usos da informática, muitas relatadas por LOPES (1997). Dentre essas, destaca-se o desenvolvimento de sistemas computacionais, visando ajudar produtores e profissionais a tomarem a decisão correta. Estatísticas recentes mostraram aumento considerável na produtividade em sistemas de produção que fazem uso da informática e têm o computador como ferramenta de trabalho (LOPES, 1997).

Atualmente, os negócios agropecuários revestem-se da mesma complexidade e dinâmica dos demais seto-

\footnotetext{
${ }_{1}$ Professor do Departamento de Medicina Veterinária da Universidade Federal de Lavras (UFLA); Doutorando em Zootecnia - Produção Animal (UNESP/FCAV - Jaboticabal); Bolsista PICDT - CAPES. Caixa postal 37, Lavras, MG, 37200-000. Telefax: (035) 8291148; E-mail:malopes@ufla.br

${ }^{2}$ Bacharel em Informática; Diretor da SIN (Soluções Informatizadas para Negócios).

${ }^{3}$ Professor da Universidade Federal de Lavras - UFLA.

4 Técnica em Contabilidade e Técnica em Processamento de Dados.
} 
res da economia, requerendo do produtor de leite nova visão da gestão dos seus negócios, principalmente pela necessidade de abandonar a posição tradicional de fazendeiro, para assumir o papel de empresário rural (YAMAGUCHI e CARNEIRO, 1997).

HOFFMANN et al. (1981) definiram custo, para fins de análise econômica, como a compensação que os proprietários dos fatores de produção, utilizados por uma empresa para produzir determinado bem, devem receber para continuar fornecendo esses fatores à mesma.

A determinação do custo de produção do leite de um sistema de produção é tarefa bastante complexa e demorada, pois envolve grande número de cálculos e detalhes e requer muita atenção. Diante disso, LOPES e LOPES (1999) desenvolveram um sistema computacional, na forma de planilhas eletrônicas, utilizando o Microsoft ${ }^{\circledR}$ Excel $^{\circledR}$. Esses autores concluíram que o sistema desenvolvido pode auxiliar o técnico e ou pecuarista na determinação do custo de produção do leite.

Considerando as menores praticidade e facilidade de operação das planilhas eletrônicas, bem como a restrição na elaboração e emissão de relatórios, quando comparadas a softwares desenvolvidos utilizando programação orientada para objetos, resolveu-se desenvolver um software para ambiente Windows ${ }^{\circledR}$.

Os objetivos deste trabalho foram: 1) desenvolver um software para auxiliar os técnicos e produtores na determinação do custo de produção do leite e que possibilite efetuar simulações em um sistema de produção de leite e 2) apresentar o sistema computacional Custo Leite para Windows ${ }^{\circledR}$.

\section{Material e Métodos}

O Custo Leite para Windows ${ }^{\circledR}$ foi desenvolvido utilizando a ferramenta Delphi ${ }^{\circledR}$, sendo uma programação orientada para objeto, em microcomputador IBM-PC compatível, com processador 586 e $16 \mathrm{MB}$ de memória RAM.

Os cálculos do custo de produção do leite contemplaram as duas estruturas de custo de produção: Custo Total de Produção (clássica), que envolve o custo fixo e a variável utilizada por BARROS (1948), e Custo Operacional, proposta por MATSUNAGA et al. (1976) e adotada pelo Instituto de Economia Agrícola - IEA/SP (MATSUNAGA et al., 1976).

A metodologia utilizada nos cálculos de Margem Bruta, Margem Líquida e ponto de equilíbrio foi a adotada por REIS (1986). A depreciação foi calculada pelo método linear (HOFFMANN et al., 1981).

Os itens que compõem o Custo Operacional Efetivo de produção do leite foram divididos em sete grupos: Mão-de-obra, Alimentação, Sanidade, Reprodução, Ordenha, Impostos e Despesas Diversas (LOPES e LOPES, 1999).

\section{Resultados e Discussão}

O Sistema desenvolvido deve ser utilizado sobre a plataforma Windows ${ }^{\circledR} 95$ ou superior, não atendendo a plataformas anteriores, como o Windows ${ }^{\circledR} 3.11$.

As rotinas foram desenvolvidas de forma conversacional, com acesso às diversas opções, por meio de menus auto-explicativos, o que permite a operação do sistema por pessoas não-especializadas em informática, mas apenas treinadas na operação de microcomputadores. Tal fato possibilita maior uso do Sistema no meio rural, onde a informática não é muito comum (LOPES, 1997).

O menu principal, apresentado na forma de "fichas", contém as opções Despesas, Receitas \& Produção, Inventário, Análise Econômica - Resumo Geral, Gráficos \& Relatórios e Créditos (Figura 1). Para selecionar uma opção, o usuário deve posicionar o mouse e clicar sobre a opção desejada. Esse recurso facilita a operação do Sistema, mostrando ao usuário todas as opções disponíveis.

Visando maior facilidade na operação, o Custo Leite possui diversos botões, os quais, uma vez acionados, permitem ao usuário localizar os dados já cadastrados, eliminar ou inserir novos dados.

Ao selecionar a opção Despesas, é disponibilizado um menu secundário, também na forma de "fichas", contendo as opções: Mão-de-obra, Alimentação, Sanidade, Reprodução, Ordenha, Impostos, Despesas Diversas e Total de Despesas (Figura 1). Nesses grupos são realizados os cadastros das despesas da empresa rural referente ao respectivo mês. A divisão das despesas em grupos permite ao usuário monitorar as despesas do sistema de produção de leite, mês a mês, auxiliando o técnico e/ou produtor em uma análise mais detalhada, objetivando encontrar possíveis pontos de estrangulamento.

Cada opção, que constitui um grupo de itens, contém uma relação de insumos utilizados na atividade leiteira, com um campo destinado à digitação dos valores. Não há obrigatoriedade do preenchimento de todos os campos. Em cada grupo de despesa, há o campo Outros, que é uma opção para o usuário inserir despesas não-contempladas em cada grupo. Assim, 


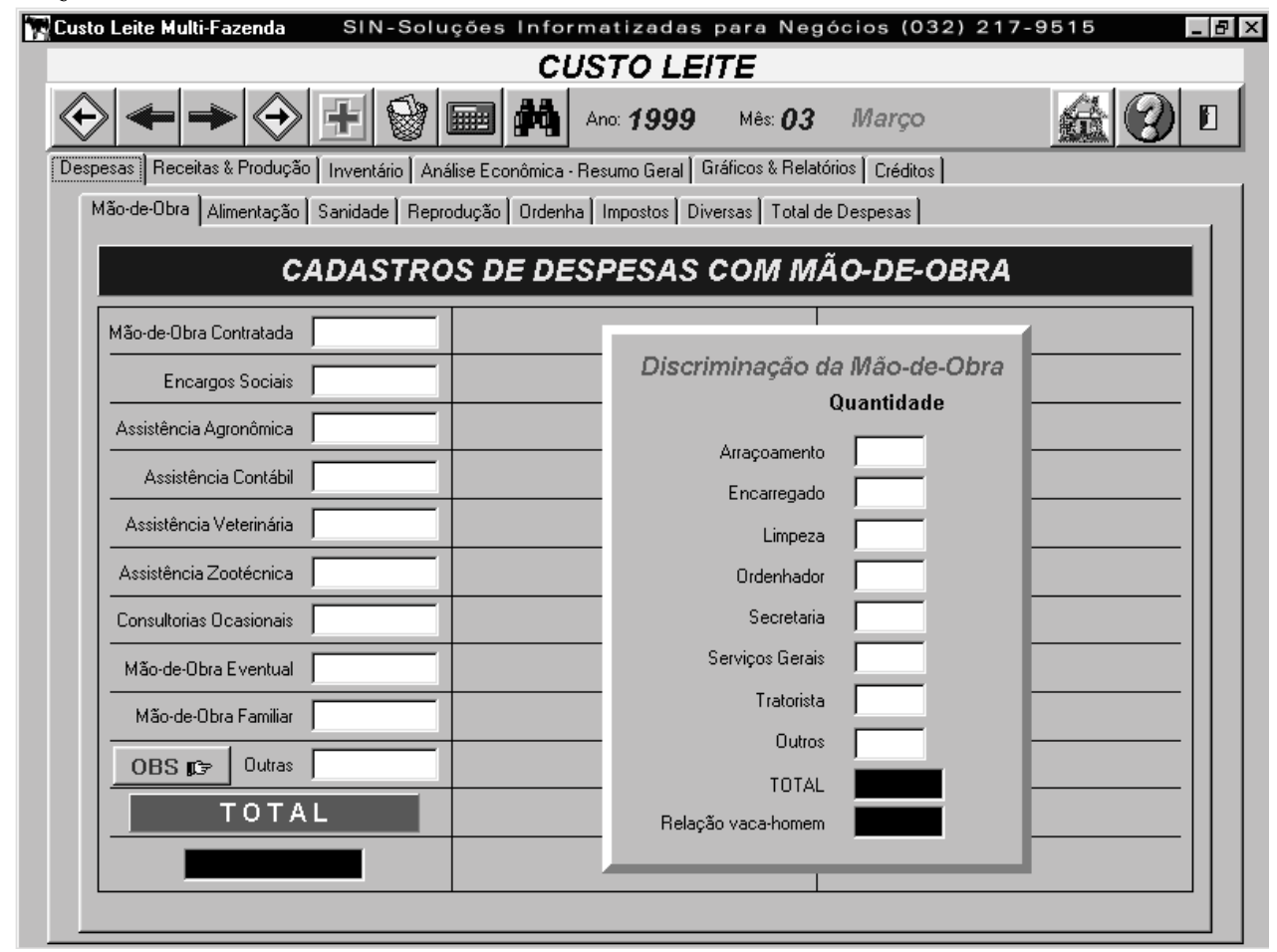

Figura 1 - Tela contendo a opção Despesas e seu menu secundário na forma de "fichas". Figure 1 - Screen containing the option Expenses and its secondary menu in the format of counter.

clicando no botão OBS, o usuário tem a opção de discriminar tais despesas.

Em Receitas \& Produção, é disponibilizado um menu secundário, contendo as opções Receitas e Produção (Figura 2). Em Receitas, o usuário deve registrar todas as receitas decorrentes da venda de leite, animais, esterco e outras que, porventura, tenham o sistema de produção. O campo Receita com vendas de animais traz um valor que é utilizado no cálculo da quantidade de "leite virtual". Esse termo, criado por LOPES e LOPES (1999), significa a quantidade de leite, em $\mathrm{kg}$, resultante da conversão dos valores apurados com as vendas de animais e esterco.

Em Produção (Figura 2), são cadastradas as quantidades totais de leite, no respectivo mês, o que constitui a quantidade de leite efetivamente produzida. Visando sos cálculos de alguns parâmetros de eficiência produtiva, o sistema requer o cadastramento de algumas informações especificadas na "ficha" Produção, como número total de matrizes do rebanho, número médio de matrizes em lactação e área do sistema de produção. Uma vez digitados os dados, o sistema Custo Leite, na mesma "ficha", mostra ao usuário alguns parâmetros de eficiência produtiva que auxiliam na tomada de decisões: total de leite produzido, total de "leite virtual", total de leite (produ- zido + virtual), produção média por matriz em lactação/ dia e produção de leite em $\mathrm{kg} / \mathrm{ha} / \mathrm{mês}$.

O usuário deve também atribuir e registrar um valor para remuneração do empresário, terra e taxa real de juros. Os valores da remuneração do empresário e da terra (REIS, 1986) são utilizados para a determinação do custo de oportunidade do capital, e a taxa real de juros, para remunerar o capital de giro e o capital investido.

Ainda em Produção, o usuário deve registrar os preços recebidos pelos diferentes tipos de leite comercializados pelo produtor. O campo Preço Médio, calculado pelo Sistema, traz o valor médio do leite recebido pelo produtor. Esse valor é uma média ponderada calculada em função dos preços dos diferentes tipos de leite fornecidos pelo produtor e das suas respectivas quantidades.

Em Inventário, o usuário deve cadastrar todos os bens móveis e benfeitorias do sistema de produção de leite, preenchendo os campos: Descrição, Caracterização do Inventário, Quantidade, Data, Valor unitário, Vida útil e Valor unitário de sucata (Figura 3). Os demais campos (Valor de aquisição, Valor total de sucata, Depreciação ao mês e Depreciação ao ano) são preenchidos automaticamente pelo Custo Leite.

Cada descrição é classificada segundo um grupo 


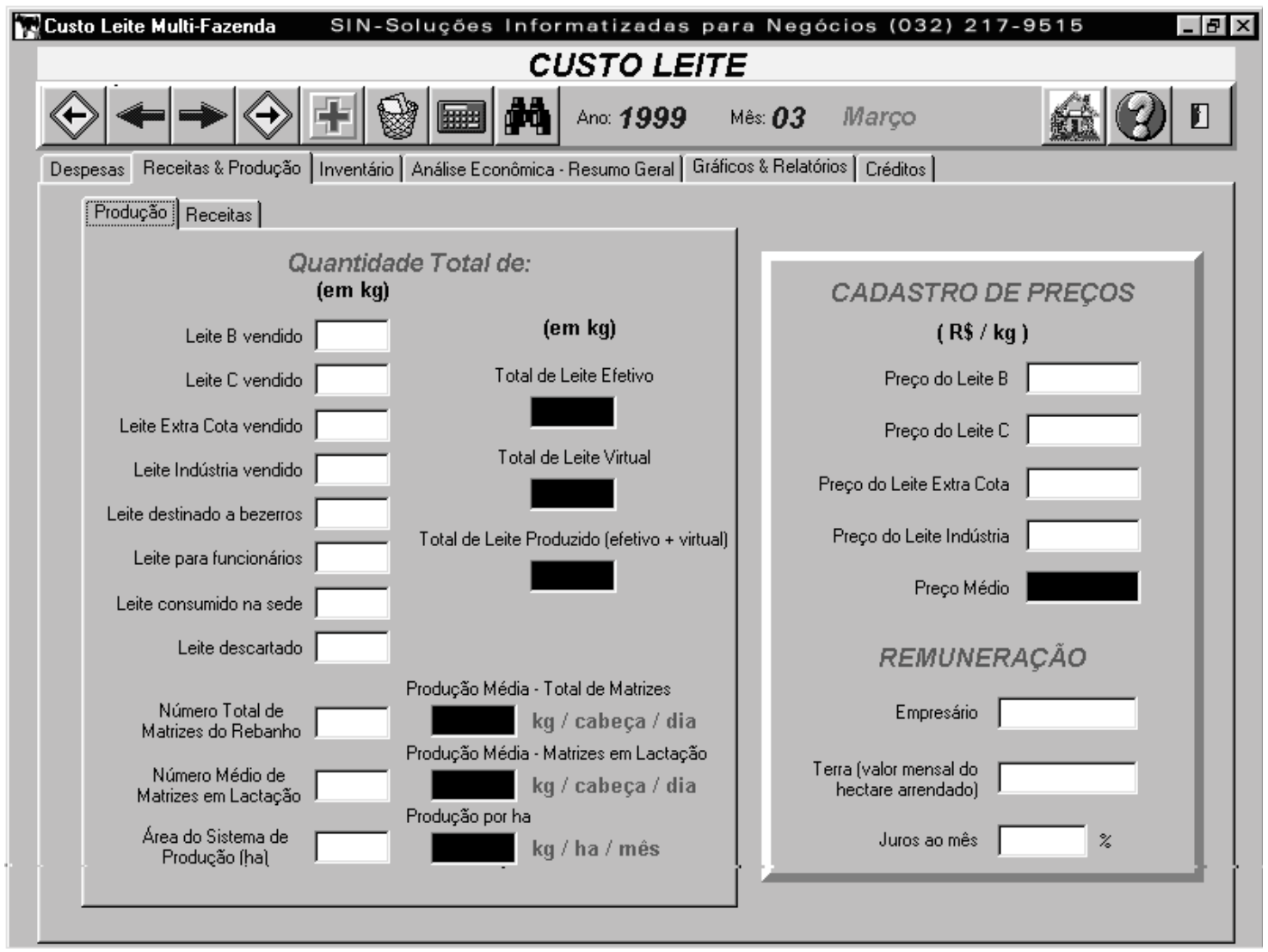

Figura 2 - Tela contendo a opção Receitas \& Produção e seu menu secundário. Figure 2 - Screen containing the option Incomes \& Production and its secondary menu.

básico do inventário, já pré-definido pelo Sistema. Ao clicar sobre o botão Calcula Sub-totais (Figura 3), é apresentado, na porção inferior da tela, um quadroresumo do inventário classificado segundo os grupos. Caso ocorram alterações na edição dos campos, há a necessidade de clicar novamente no botão Calcula Sub-totais, para a atualização do quadro-resumo.

O preenchimento correto dessa "ficha", além de proporcionar maior precisão nos cálculos, dá ao produtor o valor real do patrimônio e do capital investido na atividade leiteira. Devem ser cadastrados apenas os bens utilizados na atividade leiteira. Caso um bem seja utilizado também em outra atividade da propriedade, deve ser atribuído, por meio de rateamento, um valor para a atividade leiteira, o qual deve ser o utilizado pelo Custo Leite.

O cadastro do inventário é um importante item, pois esses valores são utilizados pelo Custo Leite para calcular a remuneração do capital investido, bem como as depreciações. Este cadastro talvez seja a tarefa mais árdua realizada pelo usuário nesse processo do cálculo do custo da produção do leite.
Todavia, vale ressaltar que esta tarefa é realizada apenas uma vez por ano, ou por ocasião da aquisição de um bem, e não mês a mês, como as demais.

Na opção Análise Econômica - Resumo Geral, é gerada toda a análise econômica do sistema de produção de leite. Diversos resultados referentes a uma análise econômica da atividade leiteira e indicadores de desempenho técnico são mostrados ao usuário (Figura 4). Estes resultados permitem avaliar e orientar as decisões a serem tomadas pelo produtor e ou pelo técnico. Nesta "ficha", são apresentados os seguintes resultados:

\section{- Total das Receitas}

- Custo Operacional Total

- Custo Operacional Efetivo

- Custo com Depreciação

- Custo Total

- Custos Fixos

- Remuneração da Terra

- Remuneração do Capital Investido

- Remuneração do Empresário 


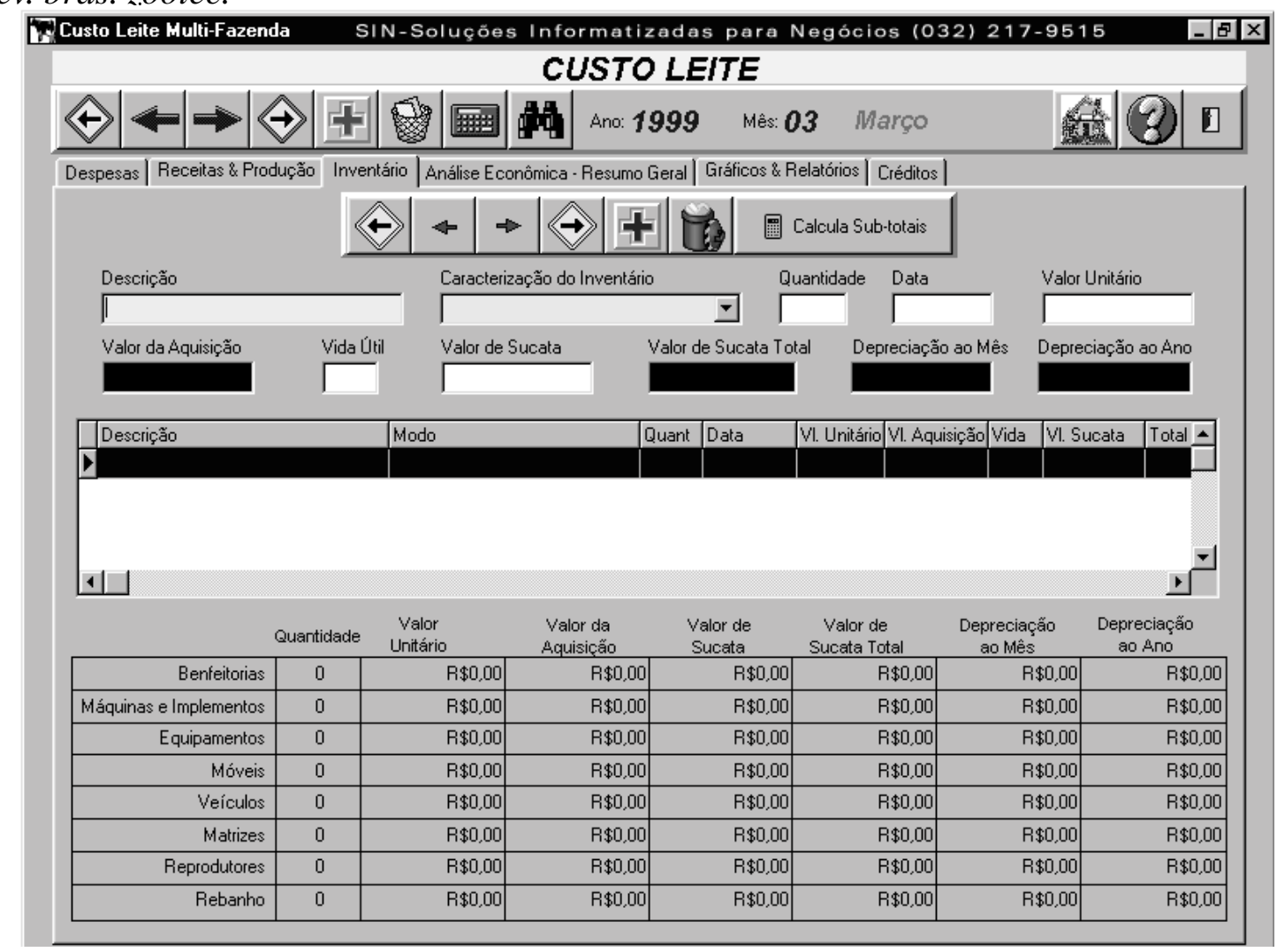

Figura 3 - Tela contendo a opção Inventário.

Figure 3 - Screen containing the option Inventory.

- Impostos

- Depreciação

- Custos Variáveis

- Custo Operacional Efetivo (excetuando Impostos)

- Remuneração do Capital de Giro

- Margem Bruta

- Margem Líquida

- Resultado (lucro ou prejuízo)

- Ponto de Equilíbrio

- Produção Total menos Ponto de Equilíbrio

Os seguintes custos médios (ou unitários), por quilograma de leite, são calculados e podem ser observados na "ficha" Análise Econômica-Resumo Geral: custo operacional total, custo operacional efetivo e custo total. O custo total do leite efetivamente produzido, mais a quantidade de leite "virtual", também é calculado. Esse valor pode ser tomado como referência para o produtor avaliar se a atividade leiteira como um todo, principalmente a cria e recria de animais, é viável economicamente.

Acionando Gráficos \& Relatórios (Figura 5), o usuário pode solicitar ao Sistema os seguintes gráficos: receita $\mathrm{x}$ custo $\mathrm{x}$ lucro; produção $\mathrm{x}$ ponto de equilíbrio; despesa mensal discriminada; receita mensal; custo total; e produção efetiva menos ponto de equilíbrio. Os seguintes relatórios são gerados: resumo geral - análise econômica; receita mensal; produção mensal; despesas mensais; e descrição do inventário.

Visando melhor e mais detalhada análise, o Sistema emite os diversos relatórios e gráficos, imprimindo-os diretamente em impressora e ou em arquivo. Esse recurso possibilita melhor armazenamento da documentação gerada e aumenta as possibilidades de transmissão dos dados, por meio de facsimile, fax modem e internet. Os relatórios e gráficos podem também ser visualizados na tela. 
LOPES et al.

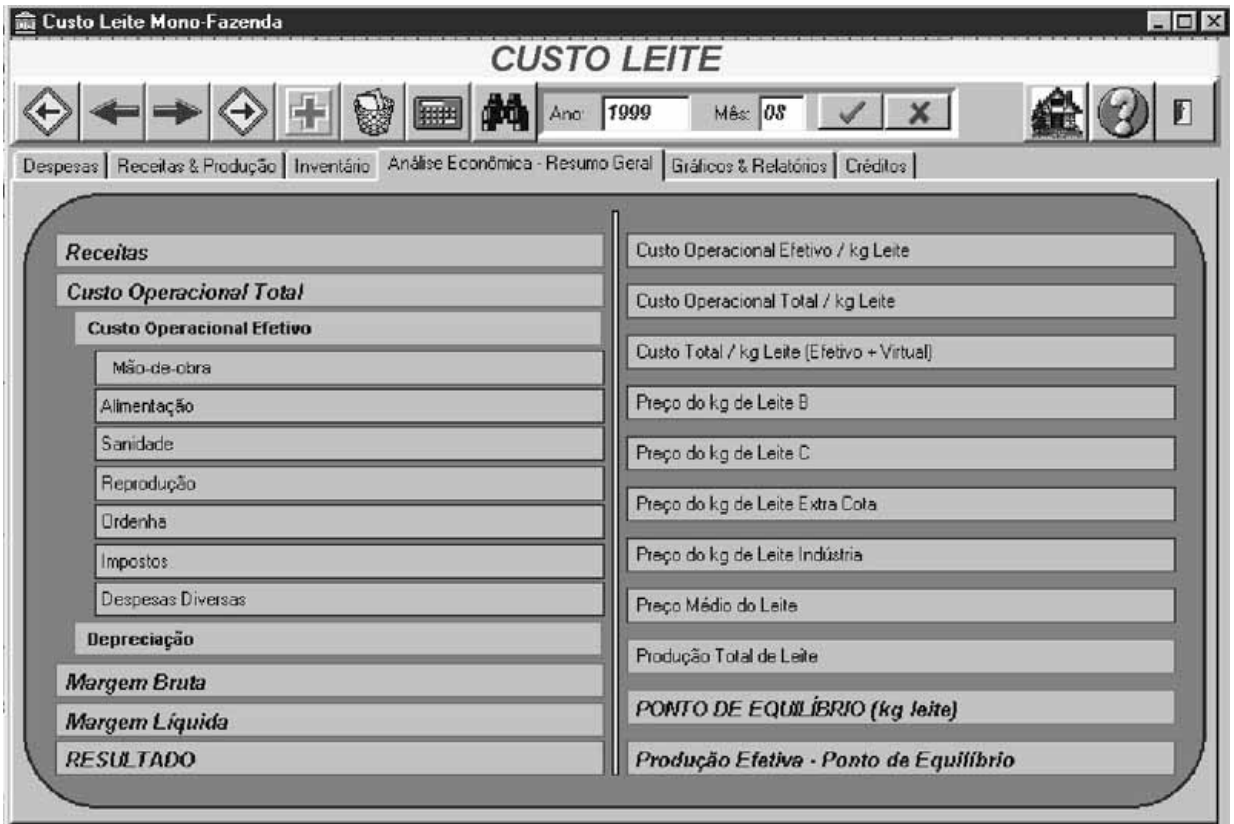

Figura 4 - Tela contendo a opção Análise Econômica - Resumo Geral/Custo Operacional. Figure 4 - Screen containing the option Economical Analysis - GeneralSummary/Operational Cost.

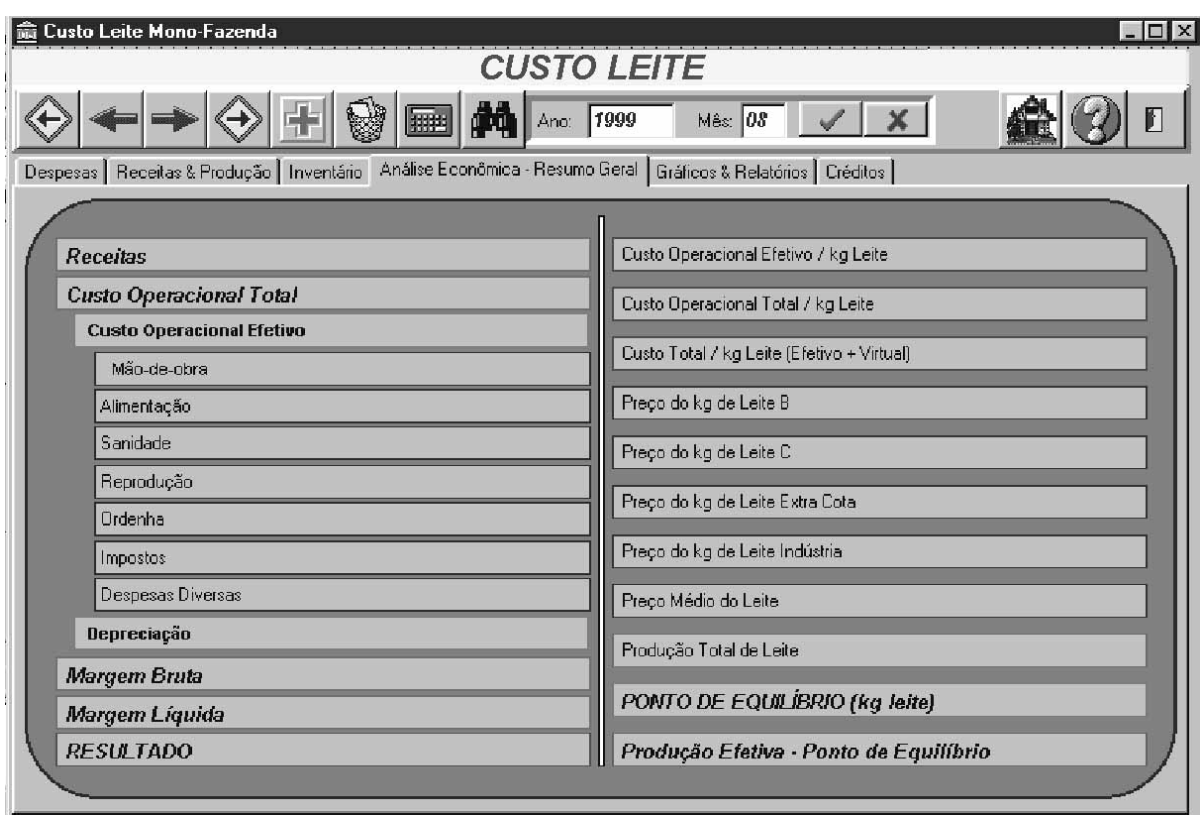

Figura 5 - Tela contendo a opção Análise Econômica - Resumo Geral/Custo Total. Figure 5 - Screen containing the option Economical Analysis - General Summary/otal Cost. 


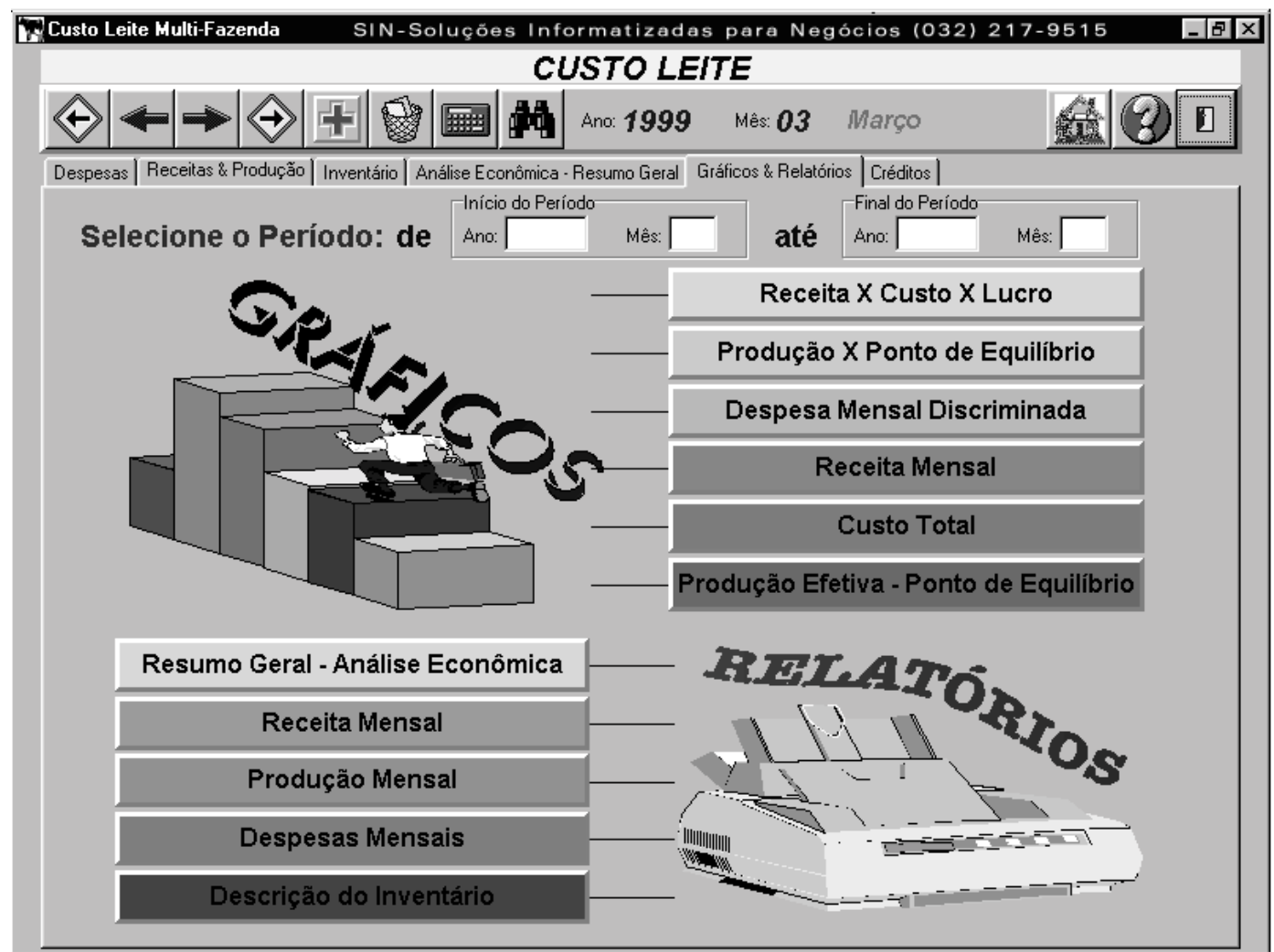

Figura 6 - Tela contendo a opção Gráficos \& Relatórios.

Figure 6 - Screen containing the option Graphics \& Reports

\section{Conclusões}

O sistema computacional desenvolvidoé importante ferramenta que auxilia o técnico e o pecuarista na determinação do custo de produção do leite, fornece informações importantes para a tomada de decisões pelos pecuaristas e permite ao usuário diversas simulações englobando todos os parâmetros e variáveis envolvidas em um sistema de produção de leite.

\section{Referências Bibliográficas}

ANTUNES, L.M., ANGEL, A. 1995. A informática na agropecuária. Canoas: Gráfica e Editora Interclubes. 157p. BARROS, H. 1948. Economia Agrária. Lisboa: Livraria Sá da Costa.

HOFFMANN, R., ENGLER, J.J.C., SERRANO, O. et al. 1981. Administração da empresa agrícola. 3.ed. São Paulo: Livraria Pioneira. 325p.
LOPES, M.A. 1997. Informática aplicada à bovinocultura. Jaboticabal: FUNEP. 82p.

LOPES, M. A., LOPES, D. de C. F. 1999. Desenvolvimento de um sistema computacional para cálculo do custo de produção do leite. Rev. Bras. Agroinformática, 2(1):1-12.

MATSUNAGA, M., BEMELMANS, P.F., TOLEDO, P.E.N. et al. 1976. Metodologia de custo de produção utilizado pelo IEA. Agricultura em São Paulo, 23(1):123-139.

REIS, D.L. dos. 1986. Estudo técnico e econômico da propriedade rural. Inf. Agropec., 12(143):23-38.

YAMAGUCHI, L.C.T., CARNEIRO, A.V. Aplicação de planilha eletrônica na análise técnica e econômica de unidades de produção de leite. In: CONGRESSO DA SOCIEDADE BRASILEIRA DE INFORMÁTICA APLICADA À AGROPECUÁRIA E À AGROINDÚSTRIA, 1, 1997, Belo Horizonte. Anais.. Belo Horizonte: SBIAGRO, 1997. p.95-99.

Recebido em: 12/04/99

Aceito em: 01/10/99 